\title{
The Elusive Role of the Left Temporal Pole (BA38) in Language: A Preliminary Meta-Analytic Connectivity Study
}

\author{
Alfredo Ardila, ${ }^{1}$ Byron Bernal, ${ }^{2}$ and Monica Rosselli ${ }^{3}$ \\ ${ }^{1}$ Department of Communication Sciences and Disorders, Florida International University, \\ 11200 SW 8th Street, AHC3-431B, Miami, FL 33199, USA \\ ${ }^{2}$ Department of Radiology/Research Institute, Miami Children's Hospital, Miami, FL, USA \\ ${ }^{3}$ Department of Psychology, Florida Atlantic University, Davie, FL, USA
}

Correspondence should be addressed to Alfredo Ardila; ardilaalfredo@gmail.com

Received 26 August 2014; Revised 4 October 2014; Accepted 7 October 2014; Published 21 October 2014

Academic Editor: João Quevedo

Copyright (C) 2014 Alfredo Ardila et al. This is an open access article distributed under the Creative Commons Attribution License, which permits unrestricted use, distribution, and reproduction in any medium, provided the original work is properly cited.

\begin{abstract}
It has been suggested that the left temporal pole (Brodmann area 38 (BA38)) participates in diverse language functions, including semantic processing, speech comprehension, and naming. Utilizing the activation likelihood estimation (ALE), a meta-analytic connectivity study was conducted to further our understanding on the role of BA38 in language. Departing from the BrainMap functional database, 11 papers corresponding to 12 paradigms including 201 participants were selected. Initially, $P<0.01$ was employed as the significance level, resulting in the presence of four different activation clusters. However, when the significance level was lowered to $P<0.05$, sixteen activation clusters appeared, including classical language areas such as Broca's and Wernicke's areas. It was concluded that (1) this meta-analytic connectivity study suggests the presence of two major connection circuits involving BA38; one is related to language, while the other may be involved in visuospatial and integrative audiovisual functions. Furthermore, (2) BA38 also contributes to various brain networks supporting linguistic processes related not only to language comprehension but also to language production.
\end{abstract}

\section{Introduction}

The temporal lobe is a particularly complex brain area involved in a diversity of functions, some of which include auditory, olfactory, memory, vestibular, visual, and linguistic processing $[1,2]$. With regard to other primates, the temporal lobe is the largest in humans representing about $17 \%$ of the cerebral cortex [3]. The temporal pole (Brodmann area 38; BA38) represents no more than $10 \%$ of total temporal lobe volume and about $1.7 \%$ of the cerebral cortex. Due to its sizeable nature, several subareas have been distinguished in the temporal pole. Pascual et al. [4] proposed separation possibilities between different cytoarchitectonic subfields: (1) dorsal, with predominant connectivity to auditory/somatosensory and language networks; (2) ventromedial, predominantly connected to visual networks; (3) medial, connected to paralimbic structures; and (4) anterolateral, connected to the default-semantic network. Consequently, significant language roles of BA38 are assumed.
The specific linguistic role of the left temporal pole remains elusive. Regardless of its evident participation in the brain language system, the left BA38 is not usually included in Wernicke's area. Nevertheless, various linguistic functions have been related to this brain area. Contemporary neuroimaging studies suggest that the left BA38 is involved in the following language-related functions: semantic processing [5-8], speech comprehension, responsive naming [9], naming of items learned in early life, word retrieval for specific entities [10], lexicosemantic ambiguity processing [11], processing negative sentences [12], narrative comprehension [13-15], and the processing of abstract information [16].

Clinical observations have significantly advanced the understanding of left temporal pole function. Analyses of individuals with left-hemisphere strokes have revealed the left anterior temporal cortices role in syntactic processing. Patients with brain damage to this area are more likely to present with receptive agrammatism than patients in which 
anterior temporal cortex remains spared [17]. It has been further proposed that the temporal pole represents a semantic hub of the brain, or the neural substrates that subserve participating in the processing of "unique entities" (i.e., proper names of people and places) [18-21]. Tsapkini et al. [22] compared a group of 20 patients with acute anterior temporal pole stroke damage to a group of 28 patients without anterior temporal pole damage matched by infarct volume. The authors calculated the average percent error in two language tasks, auditory comprehension and naming tasks, as a function of infarct volume using a nonparametric regression method. They attributed infarct volume as the sole predictive variable in the production of semantic errors in both auditory comprehension and object naming tasks. These findings were interpreted as support to the hypothesis that left unilateral anterior temporal pole lesions, even acutely, are unlikely to cause significant deficits in mapping meaning to sound by themselves although they contribute to networks underlying both naming and comprehension of objects. They concluded that the anterior temporal lobe may be a semantic hub for object meaning, but its role must be represented bilaterally.

Other authors (e.g., [23]) have reported that naming performance in a typical confrontation naming test (i.e., Boston Naming Test) is related to metabolite levels in the anterior left temporal pole. Nonetheless, some authors have argued that the role of the temporal lobe in naming is limited to the naming of unique entities, such as naming people [24]. However, some contradictory evidence has also been presented [25].

As reported in the semantic subtype of primary progressive aphasia-which is characterized by the progressive deterioration of word comprehension, particularly nouns while other cognitive abilities remain spared-marked temporopolar atrophy and pronounced impairments of odor naming and matching are observed [26]. These authors predicted that the temporal pole would play a key role in linking odor object representations to transmodal networks, given its anatomical proximity to olfactory and visual object processing areas.

Interestingly, the temporal poles are among brain regions often considered as the brain network sustaining our ability to understand other people's mental states or "Theory of Mind" (ToM) (e.g., [27, 28]). However, it has also been reported that the left temporal lobe is not necessary for ToM reasoning, at least in nonverbal conditions, as long as its right counterpart is preserved [29].

Pinpointing the connectivity of the anterior temporal lobe represents a crucial question to understand its role in language-like function. Using high angular resolution diffusion imaging (HARDI) MRI, Makris et al. [30, 31] described two major fiber connections of the human middle longitudinal fascicle. They did so by examining morphology, topography, cortical connections, biophysical measures, volume, and length in seventy-four brains. These two fiber connections course together through the dorsal temporal pole and the superior temporal gyrus maintaining a characteristic topographic relationship in the mediolateral and ventrodorsal dimensions. The authors suggested that the superior temporal-angular connection of the middle longitudinal fascicle plays a role in language and attention, while the superior temporal-superior parietal connection is involved in visuospatial and integrative audiovisual functions. Menjot De Champfleu et al. [32] reported that the middle longitudinal fasciculus is clearly delineated from the other fascicles that constitute the language pathways, especially the ventral pathway. It runs within the superior temporal gyrus white matter from the temporal pole and then extends caudally in the upper part of the sagittal stratum and the posterior part of the corona radiata to reach the inferior parietal lobule (angular gyrus). Augustine [33] emphasized the relationship between the temporal pole and the insula. Although the insula is recognized for its language responsibilities, vagueness remains regarding its participation in various language functions [34-37]. The uncinate fasciculus, on the other hand, connects the anterior temporal and inferior frontal lobes. The uncinate fasciculus connects the pole of the temporal lobe (BA38) uncus and parahippocampal gyrus with the ipsilateral orbital and lateral frontal cortices. Propositions have been made involving its association with semantic memory retrieval and processing [38].

Recently, a new alternative to study brain connectivity has been proposed by Robinson et al. [39] known as metaanalytic connectivity modeling (MACM). MACM is based in automatic meta-analysis executed by pooling coactivation patterns. The technique takes advantage of the BrainMap repository of functional MRI studies and a software program (Sleuth) provided by the same group to find, filter, organize, plot, and export peak coordinates for further statistical analysis. Sleuth provides a list of foci, in Talairach, or MNI coordinates, each one representing the center of mass of an activation cluster. This method acquires the region of interest (i.e., the temporal pole), deems it the independent variable, and interrogates the database for studies indicating comparable activation of the chosen target. The query is conveniently filtered for different conditions such as age, normal versus patients, type of paradigm, and domain of cognition. By pooling the data with these conditions, the tool is able to provide a universe of coactivations that can be statistically analyzed for significant commonality. As a final step, activation likelihood estimation (ALE) $[40,41]$ can be performed utilizing GingerALE, another software provided by BrainMap, generating probability of an event occurring at voxel level across the studies. Areas of coactivation will display a network related to the function and domains selected as filter criteria.

Considering the diverse language functions linked to BA38, a meta-analytic connectivity was developed utilizing MACM on the participation of this brain area in language. Deviating from previous clinical and neuroimaging studies, it was hypothesized that the left temporal pole participates in different brain language circuits.

Our research question is what are the areas that coactivate when BA38 activates in language tasks? With this approach, the commonality criteria are quite stringent, as it only requires BA38 activation occurrence during a language task. Notice that we were not interested in ascertaining the activation related to a specific task. The area may be 
activated in "nonverbal" tasks, but that was not explored. As a result, this concentrates the results on language domains. It is important to observe that BA38 may reveal restricted or ample connectivity (coactivation network) depending upon the spectrum of studies accepted to enter the pool of ALE analysis, that is, for example, only expressive, only receptive, only lexical, lexical and semantics, and so forth, but that decision depends upon the scope of the study.

\section{Materials and Methods}

The database of BrainMap [42] was accessed utilizing Sleuth 2.2 on December 10, 2013. Sleuth is software provided by BrainMap to query its database. Sleuth software was implemented in a Windows platform. This meta-analysis was intended to assess the network of coactivations in which the BA38 is involved.

The search conditions were as follows: (1) studies reporting BA38 activation; (2) studies using fMRI; (3) context: normal subjects; (4) activation: activation only; (5) handedness: right-handed subjects; (6) age: 20-60 years; (7) domain: cognition, subtype: language.

ALE meta-analysis was then performed utilizing GingerALE. ALE maps were initially thresholded at $P<$ 0.01 corrected for multiple comparisons and false discovery rates. We used the predefined values found in GingerALE [40] and only clusters of 200 or more cubic mm were accepted as valid clusters. ALE results were overlaid onto an anatomical template suitable for MNI coordinates, also provided by http://brainmap.org/. For this purpose, we utilized the Multi-Image Analysis GUI (Mango) (http://ric.uthscsa.edu/mango/). Mosaics of $5 \times 7$ insets of transversal fusioned images were generated utilizing a plugin of the same tool, selecting every other image, starting on image number 10, and exported to a 2D-jpg image. Because of the limited activation observed when employing the $P<0.01$ threshold, a second analysis was performed with a lowered significance level of $P<0.05$.

\section{Results}

3.1. First Analysis. Eleven papers corresponding to 12 experimental conditions with a total of 201 subjects were finally selected (subjects participating in two different experiments were counted as two subjects) (Table 1).

Table 2 presents the main loci of brain connectivity of BA38 by meta-analytic connectivity modeling (MACM). Four different clusters of activity were found, two in the left and two in the right hemisphere.

As indicated in Table 2, the first cluster includes BA38, while the second cluster contains the left insula and superior temporal lobe, indicating its involvement in language. The last two clusters include the right parietal and temporal lobes. Seemingly, this area has two major connection pathways: one within the left hemisphere and the second involving the right hemisphere.

3.2. Second Analysis. Table 3 presents the main loci of brain connectivity of BA38 by meta-analytic connectivity modeling
(MACM) when significance level $P<0.05$ was selected. Sixteen different clusters of activity were found.

The first clusters include basically the same areas found in the first analysis. Thus, there is one connection pathway in the left including the insula and the temporal lobe and another connection pathway to the right including the parietal and temporal lobes. Some increased activation is also found at the level of the claustrum, probably as an extension of some insula activation. Other additional clusters of activation are located within the left occipital area (BA17), frontal language areas (BA44 and BA47), subcortical areas such as the caudate nucleus and even brainstem areas (red nucleus), Wernicke's area (left BA22), and homologous right area (right BA22).

\section{Discussion}

It is well known that BA38 has some participation in language, although pinpointing its specific function has been not easy. It has been suggested that one of its major language functions includes naming, particularly the naming of unique entities (i.e., names of people and places) [18-21]. Interestingly, naming using fingerspelling and signing by native ASL signers have also shown that naming famous persons activates the left temporal pole, whereas naming animals (whether fingerspelled or signed) activates the left inferotemporal cortex [54]. This observation demonstrates that left BA38 function in naming is not exclusively dependent on the auditory information of language but is a more general and conceptual one.

Functional studies have advanced the understanding of the unexpected complexity of BA38 functions (see [55]). Because of its location in the brain (somehow in between Broca's and Wernicke's areas), it is understandable that BA38 participates in language. Our first meta-analytic study is congruent with Makris et al. [30, 31] observation that two fiber connections course through the temporal pole; one is involved in language (superior temporal-angular connection of the middle longitudinal fascicle), while the other is involved in visuospatial and integrative audiovisual functions (superior temporal-superior parietal connection).

It was unexpected to find so few activation clusters in the first meta-analysis and so many activation clusters in the second meta-analysis. This observation may suggest that the left temporal pole has two fundamental connections; thus, it participates in the following two major brain networks: one related to language and the other related to more visuospatial and integrative audiovisual functions, as it has been suggested by Makris et al. [30, 31]. Moreover, BA38 may also have a secondary contribution to several networks supporting linguistic processes and it may be related not only to language understanding but also to language production. Indeed, both Wernicke and Broca's areas appeared interconnected to left BA38.

Interestingly, two different pathways in language processing have been recognized. Electrophysiological analysis of the auditory system in primates and functional neuroimaging studies in human subjects have suggested that there are two pathways arising from the primary auditory cortex; a "ventral" pathway is thought to project anteriorly from 
TABLE 1: Primary studies of language-related paradigms included in the meta-analysis (11 studies; 12 paradigms; 201 subjects).

\begin{tabular}{llcc}
\hline Publication & Paradigm & $n$ & Foci \\
\hline Noppeney and Price, 2004 [43] & Abstract Concepts > Sounds & 15 & 4 \\
Kensinger and Schacter, 2006 [44] & Items Corresponding Subseq Item & 21 & 6 \\
Ghosh et al., 2008 [45] & Bisyllables > Monosyllables & 10 & 38 \\
Leff et al., 2008 [46] & (Idioms + Rearranged Idioms) & 26 & 10 \\
Simmons et al., 2008 [47] & Situation Generation > Word Assoc & 10 & 23 \\
Benoit et al., 2010 [48] & Word generation & 16 & 26 \\
Binder et al., 2005 [49] & Incongruent Non-McGurk-Incongruent & 12 \\
Lieberman et al., 2007 [50] & Correlation Reading Activ \& RespTime & 42 \\
Sabsevitz et al., 2005 [51] & Gender Labeling > Affect Labeling & 30 & \\
Nil et al., 2008 [52] & Abstract > Concrete & 28 \\
Kensinger and Schacter, 2005 [53] & Listen minus Baseline & 14 \\
\hline
\end{tabular}

TABLE 2: Main loci of brain connectivity of BA38 in language tasks by meta-analytic connectivity modeling (MACM).

\begin{tabular}{|c|c|c|c|c|c|}
\hline $\begin{array}{l}\text { Cluster \# } \\
\text { region (BA) }\end{array}$ & $x$ & $y$ & $z$ & ALE & Volume $\left(\mathrm{mm}^{3}\right)$ \\
\hline C \#1 L suptemporal (38) & -52 & 8 & -18 & 0.0171 & 536 \\
\hline \multicolumn{6}{|l|}{$\mathrm{C} \# 2$} \\
\hline L insula (13) & -40 & 8 & -14 & 0.01552 & 393 \\
\hline L suptemporal (22) & -34 & 4 & -20 & 0.01355 & \\
\hline C \#3 R supparietal (7) & 22 & -68 & 52 & 0.017807 & 368 \\
\hline $\mathrm{C} \# 4 \mathrm{R}$ midtemporal (21) & 50 & -2 & -22 & 0.016548 & 288 \\
\hline
\end{tabular}

TABLE 3: Main loci of brain connectivity of BA38 when using $P<0.05$.

\begin{tabular}{|c|c|c|c|c|c|}
\hline $\begin{array}{l}\text { Cluster \# } \\
\text { region (BA) }\end{array}$ & $x$ & $y$ & $z$ & ALE & Volume $\left(\mathrm{mm}^{3}\right)$ \\
\hline C \#1 L superior temporal (38) & -52 & 8 & -18 & 0.017151 & 1128 \\
\hline \multicolumn{6}{|l|}{$\mathrm{C} \# 2$} \\
\hline L insula (13) & -40 & 8 & -14 & 0.01552 & \multirow[t]{2}{*}{918} \\
\hline L superior temporal (38) & -14 & 4 & -20 & 0.01355 & \\
\hline C \#3 R parietal (7) & 22 & -68 & 52 & 0.017807 & 862 \\
\hline $\mathrm{C}$ \#4 R claustrum & 32 & 20 & 0 & 0.012655 & 592 \\
\hline C \#5 R middle temporal (21) & 50 & -2 & -22 & 0.016548 & 576 \\
\hline C \#6 L occipital (17) & -26 & -82 & 18 & 0.012529 & 464 \\
\hline C \#7 R. suptemporal (38) & 42 & 12 & -32 & 0.012064 & 432 \\
\hline \multicolumn{6}{|l|}{$\mathrm{C} \# \mathbf{8}$} \\
\hline R suptemporal (13) & 50 & -18 & 8 & 0.012939 & \multirow[t]{2}{*}{376} \\
\hline $\mathrm{R}$ insula (13) & 44 & -14 & 2 & 0.009738 & \\
\hline C \#9 L inferior frontal (47) & -48 & 26 & -8 & 0.01192 & 368 \\
\hline $\mathrm{C} \# 10 \mathrm{R}$ red nucleus & 4 & -24 & -2 & 0.01438 & 336 \\
\hline C \#11 L parietal (40) & -38 & -46 & 40 & 0.013404 & 296 \\
\hline C\#12 L caudate tail & -38 & -14 & -16 & 0.011972 & 272 \\
\hline C \#13 R cingulate gyrus (32) & 8 & 18 & 42 & 0.013608 & 272 \\
\hline C \#14 L frontal precentral (44) & -54 & 16 & 6 & 0.011838 & 256 \\
\hline C \#15 R suptemporal (22) & 64 & -42 & 12 & 0.012893 & 216 \\
\hline C \#16 L suptemporal (22) & -64 & 20 & 0 & 0.011586 & 200 \\
\hline
\end{tabular}


the primary auditory cortex to prefrontal areas along the superior temporal gyrus, while a separate "dorsal" route connects these areas posteriorly via the inferior parietal lobe. A similar pattern of pathways has been found in humans: a dorsal pathway from Wernicke's area to Broca's area including the arcuate fasciculus, the supramarginal gyrus, the lateral superior temporal gyrus, and the lateral middle temporal gyrus. Additionally, a ventral route between Wernicke's area and Broca's area has been exhibited connecting these two areas through the external capsule/uncinate fasciculus and the medial superior temporal gyrus. As expected, these connections are stronger in the left hemisphere [56, 57]. BA38 language connections would correspond to the ventral pathway.

The connections found between BA38 and the association auditory areas of the right hemisphere (BA21/22) intriguingly suggest that the left temporal pole has an assortment of functions beyond the purely linguistic functions. Markedly, the right temporal pole has been included in a system involved in emotion processing, with the insula and the amygdala [58]. Pizzamiglio et al. [59] analyzed whether sounds referring to actions have a different representation in the brain from other types of sounds. By method of ERP, they found the left posterior superior temporal and premotor areas to be selectively modulated by action-related sounds. Contrastingly, the temporal pole is bilaterally modulated by nonaction-related sounds. Thus, the left temporal pole seemingly participates in a broad brain system involved in emotion and sound processing.

A significant involvement of the right hemisphere temporal lobe in emotional language is commonly accepted [60]. However, brain processing of emotional prosody seems particularly complex and probably includes the right temporal pole. The presence of three successive processing stages during recognition of emotional prosody has been postulated: (1) extraction of suprasegmental acoustic information predominantly subserved by right-sided primary and higher order acoustic regions, (2) representation of meaningful suprasegmental acoustic sequences within posterior aspects of the right superior temporal sulcus, and (3) explicit evaluation of emotional prosody at the level of the bilateral inferior frontal cortex. Explicit evaluation of linguistic aspects of prosody appears to be linked to left-hemisphere language areas. Specifically, the bilateral orbitofrontal cortex was found to be involved in explicit evaluation of emotional prosody [61]. Furthermore, it has been proposed that evaluation of affective prosody requires prior analysis of acoustic features within temporal regions and that transfer of information from the temporal cortex to the frontal lobes occurs via parallel pathways [62].

Many limitations could be mentioned regarding the present study. The major critique of meta-analysis studies commonly refers to the lack of homogeneity of the pooled tasks, methods, and individuals. Furthermore, MACM is still new requiring performance of future validation studies. We have used BA38 as the independent variable and a spectrum of coactivated areas as the dependent variable, which may be unusual. However, the current results are quite consistent with clinical observations, positively supporting the structural connectivity findings.

\section{Conflict of Interests}

The authors declare that there is no conflict of interests regarding the publication of this paper.

\section{Acknowledgment}

The authors express their most sincere gratitude to Carley Keim for her editorial support.

\section{References}

[1] K. Kolb and I. Q. Whishaw, Fundamentals of Human Neuropsychology, Worth Publishers, New York, NY, USA, 6th edition, 2009.

[2] L. R. Squire, C. E. L. Stark, and R. E. Clark, "The medial temporal lobe," Annual Review of Neuroscience, vol. 27, pp. 279306, 2004.

[3] J. A. Kiernan, "Anatomy of the temporal lobe," Epilepsy Research and Treatment, vol. 2012, Article ID 176157, 12 pages, 2012.

[4] B. Pascual, J. C. Masdeu, M. Hollenbeck et al., "Large-scale brain networks of the human left temporal pole: a functional connectivity MRI study," Cerebral Cortex, 2013.

[5] U. Noppeney and C. J. Price, "Retrieval of visual, auditory, and abstract semantics," NeuroImage, vol. 15, no. 4, pp. 917-926, 2002.

[6] U. Noppeney and C. J. Price, "A PET study of stimulus- and task-induced semantic processing," NeuroImage, vol. 15, no. 4, pp. 927-935, 2002.

[7] C. Palliera, A.-D. Devauchellea, and S. Dehaenea, "Cortical representation of the constituent structure of sentences," Proceedings of the National Academy of Sciences of the United States of America, vol. 108, no. 6, pp. 2522-2527, 2011.

[8] R. Vandenberghe, A. C. Nobre, and C. J. Price, "The response of left temporal cortex to sentences," Journal of Cognitive Neuroscience, vol. 14, no. 4, pp. 550-560, 2002.

[9] L. Tomaszewki, S. Farias, G. Harrington, C. Broomand, and M. Seyal, "Differences in functional MR imaging activation patterns associated with confrontation naming and responsive naming," American Journal of Neuroradiology, vol. 26, no. 10, pp. 2492-2499, 2005.

[10] T. J. Grabowski, H. Damasio, D. Tranel, L. L. Boles Ponto, R. D. Hichwa, and A. R. Damasio, "A role for left temporal pole in the retrieval of words for unique entities," Human Brain Mapping, vol. 13, no. 4, pp. 199-212, 2001.

[11] K. Hoenig and L. Scheef, "Mediotemporal contributions to semantic processing: fMRI evidence from ambiguity processing during semantic context verification," Hippocampus, vol. 15, no. 5, pp. 597-609, 2005.

[12] U. Kumar, P. Padakannaya, R. K. Mishra, and C. L. Khetrapal, "Distinctive neural signatures for negative sentences in Hindi: an fMRI study," Brain Imaging and Behavior, vol. 7, no. 2, pp. 91-101, 2013.

[13] J. T. Crinion, E. A. Warburton, M. A. Lambon-Ralph, D. Howard, and R. J. S. Wise, "Listening to narrative speech after aphasic stroke: the role of the left anterior temporal lobe," Cerebral Cortex, vol. 16, no. 8, pp. 1116-1125, 2006. 
[14] E. A. Maguire, C. D. Frith, and R. G. Morris, “The functional neuroanatomy of comprehension and memory: the importance of prior knowledge," Brain, vol. 122, no. 10, pp. 1839-1850, 1999.

[15] N. Tzourio, B. Nkanga-Ngila, and B. Mazoyer, "Left planum temporale surface correlates with functional dominance during story listening," NeuroReport, vol. 9, no. 5, pp. 829-833, 1998.

[16] B. Straube, Y. He, M. Steines et al., "Supramodal neural processing of abstract information conveyed by speech and gesture," Frontiers in Behavioral Neuroscience, vol. 7, article 120, 2013.

[17] S. Magnusdottir, P. Fillmore, D. B. den Ouden et al., "Damage to left anterior temporal cortex predicts impairment of complex syntactic processing: a lesion-symptom mapping study," Human Brain Mapping, vol. 34, no. 10, pp. 2715-2723, 2013.

[18] K. Patterson, P. J. Nestor, and T. T. Rogers, "Where do you know what you know? The representation of semantic knowledge in the human brain," Nature Reviews Neuroscience, vol. 8, no. 12, pp. 976-987, 2007.

[19] W. K. Simmons and A. Martin, "The anterior temporal lobes and the functional architecture of semantic memory," Journal of the International Neuropsychological Society, vol. 15, no. 5, pp. 645-649, 2009.

[20] D. Tranel, H. Damasio, and A. R. Damasio, "A neural basis for the retrieval of conceptual knowledge," Neuropsychologia, vol. 35, no. 10, pp. 1319-1327, 1997.

[21] D. Tranel, "Impaired naming of unique landmarks is associated with left temporal polar damage," Neuropsychology, vol. 20, no. 1, pp. 1-10, 2006.

[22] K. Tsapkini, C. E. Frangakis, and A. E. Hillis, "The function of the left anterior temporal pole: evidence from acute stroke and infarct volume," Brain, vol. 134, no. 10, pp. 3094-3105, 2011.

[23] L. Rami, C. Caprile, B. Gómez-Ansón et al., "Naming is associated with left temporal pole metabolite levels in neurodegenerative diseases," Dementia and Geriatric Cognitive Disorders, vol. 25, no. 3, pp. 212-217, 2008.

[24] C. Papagno, "Naming and the role of the uncinate fasciculus in language function," Current Neurology and Neuroscience Reports, vol. 11, no. 6, pp. 553-559, 2011.

[25] I. P. Martins and L. Farrajota, "Proper and common names: a double dissociation," Neuropsychologia, vol. 45, no. 8, pp. 17441756, 2007.

[26] J. K. Olofsson, E. Rogalski, T. Harrison, M.-M. Mesulam, and J. A. Gottfried, "A cortical pathway to olfactory naming: evidence from primary progressive aphasia," Brain, vol. 136, no. 4, pp. 1245-1259, 2013.

[27] S. J. Carrington and A. J. Bailey, "Are there theory of mind regions in the brain? A review of the neuroimaging literature," Human Brain Mapping, vol. 30, no. 8, pp. 2313-2335, 2009.

[28] F. Van Overwalle, "Social cognition and the brain: a metaanalysis," Human Brain Mapping, vol. 30, no. 3, pp. 829-858, 2009.

[29] C. Michel, L. Dricot, R. Lhommel et al., "Extensive left temporal pole damage does not impact on theory of mind abilities," Journal of Cognitive Neuroscience, vol. 25, no. 12, pp. 2025-2046, 2013.

[30] N. Makris, M. G. Preti, D. Wassermann et al., "Human middle longitudinal fascicle: segregation and behavioral-clinical implications of two distinct fiber connections linking temporal pole and superior temporal gyrus with the angular gyrus or superior parietal lobule using multi-tensor tractography," Brain Imaging and Behavior, vol. 7, no. 3, pp. 335-352, 2013.
[31] N. Makris, M. G. Preti, T. Asami et al., "Human middle longitudinal fascicle: variations in patterns of anatomical connections," Brain Structure and Function, vol. 218, no. 4, pp. 951-968, 2013.

[32] N. Menjot De Champfleur, I. Lima Maldonado, S. MoritzGasser et al., "Middle longitudinal fasciculus delineation within language pathways: a diffusion tensor imaging study in human," European Journal of Radiology, vol. 82, no. 1, pp. 151-157, 2013.

[33] J. R. Augustine, "Circuitry and functional aspects of the insular lobe in primates including humans," Brain Research Reviews, vol. 22, no. 3, pp. 229-244, 1996.

[34] H. Ackermann and A. Riecker, "The contribution of the insula to motor aspects of speech production: a review and a hypothesis," Brain and Language, vol. 89, no. 2, pp. 320-328, 2004.

[35] A. Ardila, "The role of insula in language: an unsettled question," Aphasiology, vol. 13, no. 1, pp. 79-87, 1999.

[36] A. Ardila, D. F. Benson, and F. G. Flynn, "Participation of the insula in language," Aphasiology, vol. 11, no. 12, pp. 1159-1169, 1997.

[37] A. Ardila, B. Bernal, and M. Rosselli, "Participation of the insula in language revisited: a meta-analytic connectivity study," Journal of Neurolinguistics, vol. 29, no. 1, pp. 31-41, 2014.

[38] A. S. Dick, B. Bernal, and P. Tremblay, "The language connectome: new pathways, new concepts," Neuroscientist, vol. 20, no. 5, pp. 453-467, 2014.

[39] J. L. Robinson, A. R. Laird, D. C. Glahn, W. R. Lovallo, and P. T. Fox, "Metaanalytic connectivity modeling: delineating the functional connectivity of the human amygdala," Human Brain Mapping, vol. 31, no. 2, pp. 173-184, 2010.

[40] A. R. Laird, P. M. Fox, C. J. Price et al., "ALE meta-analysis: controlling the false discovery rate and performing statistical contrasts," Human Brain Mapping, vol. 25, no. 1, pp. 155-164, 2005.

[41] P. E. Turkeltaub, G. F. Eden, K. M. Jones, and T. A. Zeffiro, "Meta-analysis of the functional neuroanatomy of single-word reading: method and validation," NeuroImage, vol. 16, no. 3, part 1, pp. 765-780, 2002.

[42] http://brainmap.org/.

[43] U. Noppeney and C. J. Price, "Retrieval of abstract semantics," NeuroImage, vol. 22, no. 1, pp. 164-170, 2004.

[44] E. A. Kensinger and D. L. Schacter, "Amygdala activity is associated with the successful encoding of item, but not source, information for positive and negative stimuli," Journal of Neuroscience, vol. 26, no. 9, pp. 2564-2570, 2006.

[45] S. S. Ghosh, J. A. Tourville, and F. H. Guenther, "A neuroimaging study of premotor lateralization and cerebellar involvement in the production of phonemes and syllables," Journal of Speech, Language, and Hearing Research, vol. 51, no. 5, pp. 1183-1202, 2008.

[46] A. P. Leff, T. M. Schofield, K. E. Stephan, J. T. Crinion, K. J. Friston, and C. J. Price, "The cortical dynamics of intelligible speech," Journal of Neuroscience, vol. 28, no. 49, pp. 13209-13215, 2008.

[47] W. K. Simmons, S. B. Hamann, C. L. Harenski, X. P. Hu, and L. W. Barsalou, "fMRI evidence for word association and situated simulation in conceptual processing," Journal of Physiology, vol. 102, no. 1-3, pp. 106-119, 2008.

[48] M. M. Benoit, T. Raij, F.-H. Lin, I. P. Jääskeläinen, and S. Stufflebeam, "Primary and multisensory cortical activity is correlated with audiovisual percepts," Human Brain Mapping, vol. 31, no. 4, pp. 526-538, 2010. 
[49] J. R. Binder, D. A. Medler, R. Desai, L. L. Conant, and E. Liebenthal, "Some neurophysiological constraints on models of word naming," NeuroImage, vol. 27, no. 3, pp. 677-693, 2005.

[50] M. D. Lieberman, N. I. Eisenberger, M. J. Crockett, S. M. Tom, J. H. Pfeifer, and B. M. Way, "Putting feelings into words: affect labeling disrupts amygdala activity in response to affective stimuli," Psychological Science, vol. 18, no. 5, pp. 421-428, 2007.

[51] D. S. Sabsevitz, D. A. Medler, M. Seidenberg, and J. R. Binder, "Modulation of the semantic system by word imageability," NeuroImage, vol. 27, no. 1, pp. 188-200, 2005.

[52] L. F. De Nil, D. S. Beal, S. J. Lafaille, R. M. Kroll, A. P. Crawley, and V. L. Gracco, "The effects of simulated stuttering and prolonged speech on the neural activation patterns of stuttering and nonstuttering adults," Brain and Language, vol. 107, no. 2, pp. 114-123, 2008.

[53] E. A. Kensinger and D. L. Schacter, "Retrieving accurate and distorted memories: neuroimaging evidence for effects of emotion," NeuroImage, vol. 27, no. 1, pp. 167-177, 2005.

[54] K. Emmorey, T. Grabowski, S. McCullough et al., "Neural systems underlying lexical retrieval for sign language," Neuropsychologia, vol. 41, no. 1, pp. 85-95, 2003.

[55] "Brodmann's Interactive Atlas," http://www.fmriconsulting .com/brodmann/BA5.html.

[56] G. J. Parker, S. Luzzi, D. C. Alexander, C. A. Wheeler-Kingshott, O. Ciccarelli, and M. Lambon Ralph, "Lateralization of ventral and dorsal auditory-language pathways in the human brain," NeuroImage, vol. 24, no. 3, pp. 656-666, 2005.

[57] J. P. Rauschecker and S. K. Scott, "Maps and streams in the auditory cortex: nonhuman primates illuminate human speech processing," Nature Neuroscience, vol. 12, no. 6, pp. 718-724, 2009.

[58] S. Hsieh, M. Hornberger, O. Piguet, and J. R. Hodges, "Brain correlates of musical and facial emotion recognition: evidence from the dementias," Neuropsychologia, vol. 50, no. 8, pp. 18141822, 2012.

[59] L. Pizzamiglio, T. Aprile, G. Spitoni et al., "Separate neural systems for processing action- or non-action-related sounds," NeuroImage, vol. 24, no. 3, pp. 852-861, 2005.

[60] R. D. Lane and L. Nadel, Cognitive Neuroscience of Emotion, Oxford University Press, New York, NY, USA, 2000.

[61] D. Wildgruber, H. Ackermann, B. Kreifelts, and T. Ethofer, "Chapter 13 Cerebral processing of linguistic and emotional prosody: fMRI studies," Progress in Brain Research, vol. 156, pp. 249-268, 2006.

[62] T. Ethofer, S. Anders, M. Erb et al., "Cerebral pathways in processing of affective prosody: a dynamic causal modeling study," NeuroImage, vol. 30, no. 2, pp. 580-587, 2006. 

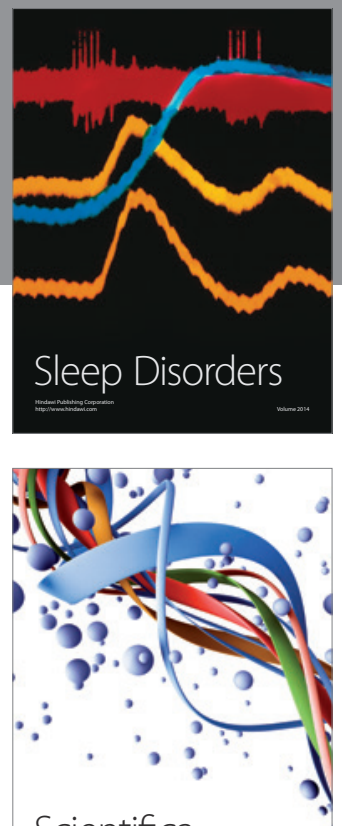

Scientifica
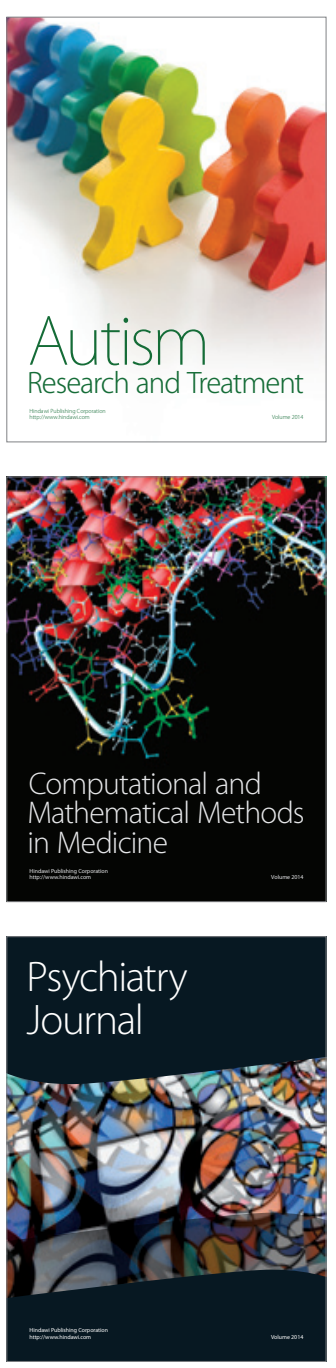
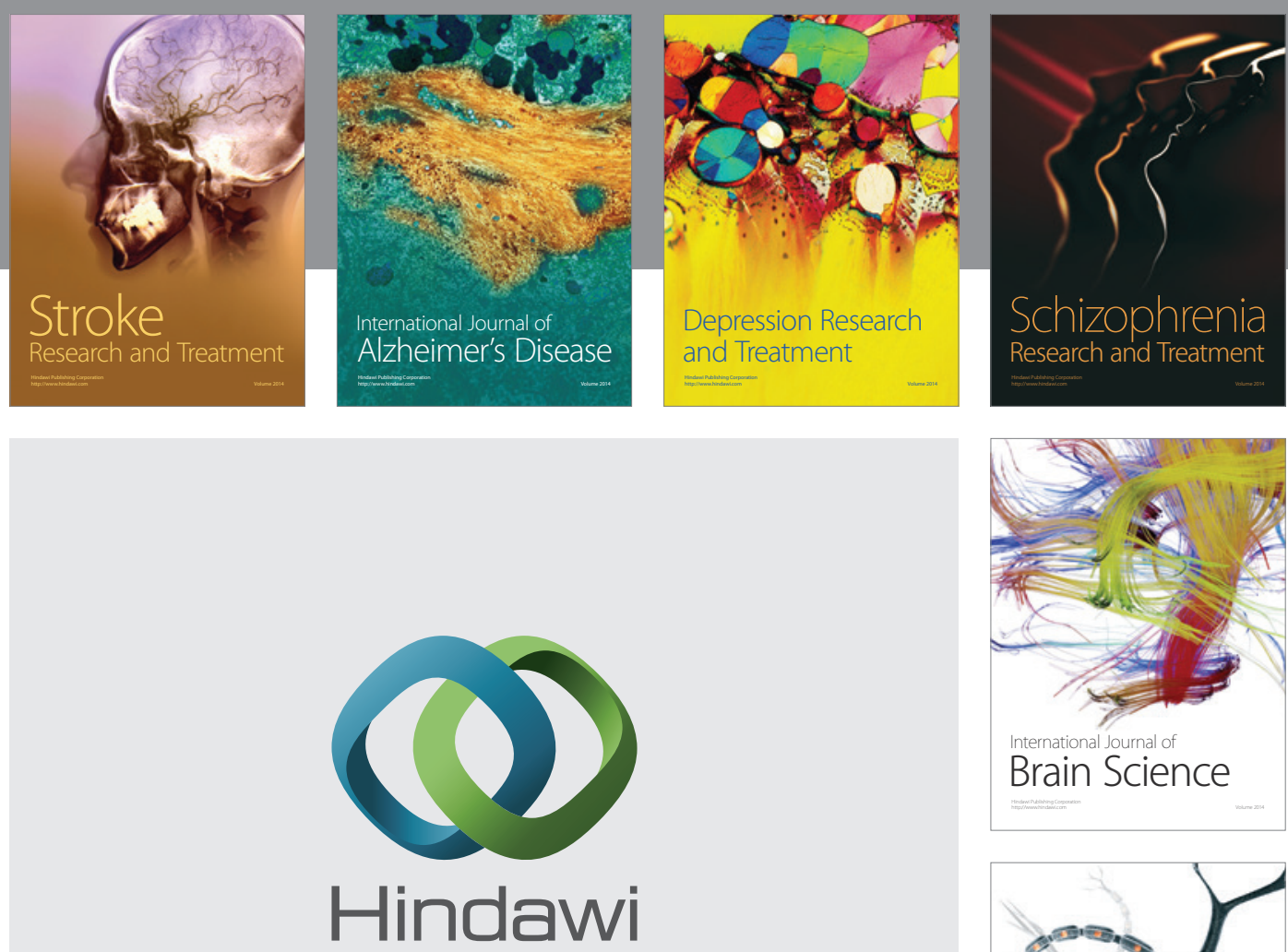

Submit your manuscripts at

http://www.hindawi.com
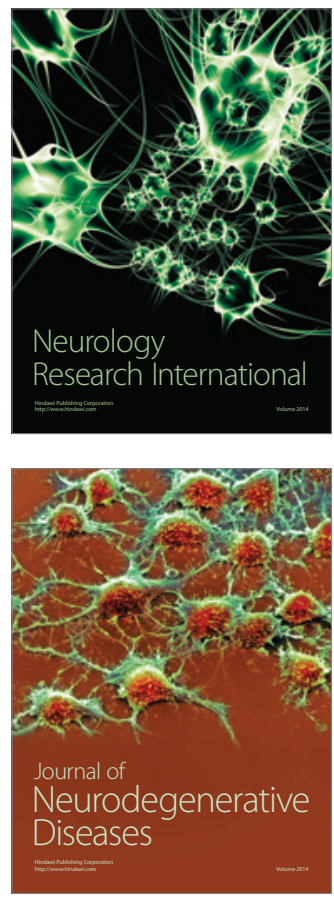

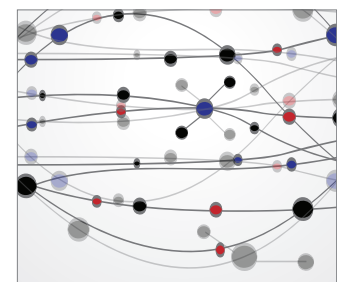

The Scientific World Journal
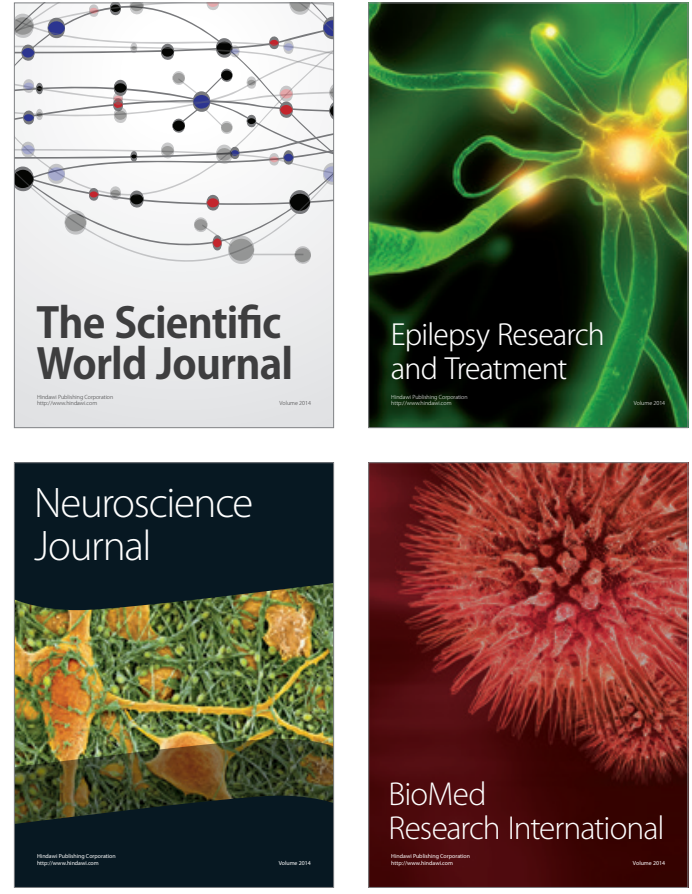

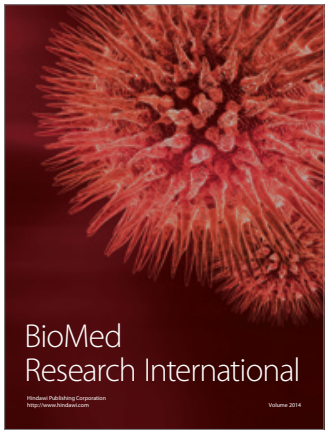

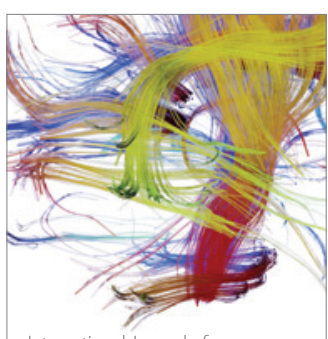

Brain Science

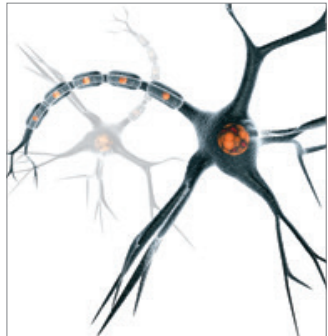

Neural Plasticity
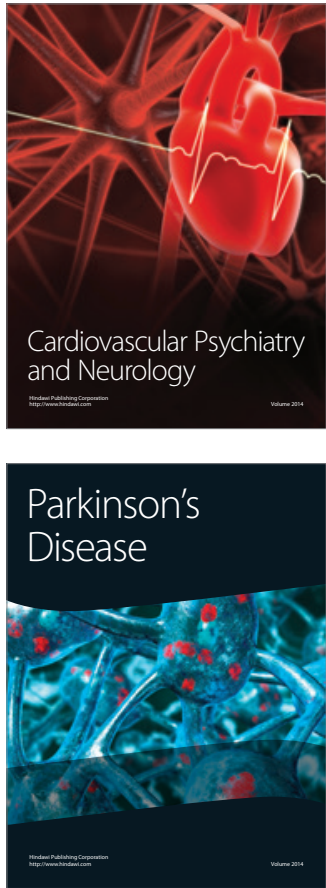